Purdue University Purdue e-Pubs

$1-21-2008$

\title{
Analytical Model for an Electrostatically Actuated Miniature Diaphragm Compressor
}

\author{
Abhijit A. Sathe \\ asathe@purdue.edu \\ Eckhard A. Groll \\ Purdue University - Main Campus, groll@purdue.edu \\ S V. Garimella \\ Purdue University, sureshg@purdue.edu
}

Follow this and additional works at: http:/ / docs.lib.purdue.edu/coolingpubs

Sathe, Abhijit A.; Groll, Eckhard A.; and Garimella, S V., "Analytical Model for an Electrostatically Actuated Miniature Diaphragm Compressor" (2008). CTRC Research Publications. Paper 65.

http://dx.doi.org/10.1088/0960-1317/18/3/035010

This document has been made available through Purdue e-Pubs, a service of the Purdue University Libraries. Please contact epubs@purdue.edu for additional information. 


\title{
Analytical model for an electrostatically actuated miniature diaphragm compressor
}

\author{
Abhijit A Sathe, Eckhard A Groll ${ }^{\dagger}$ and Suresh V Garimella \\ NSF Cooling Technologies Research Center, School of Mechanical Engineering \\ Purdue University, West Lafayette, Indiana 47907 USA
}

\begin{abstract}
This paper presents a new analytical approach for quasi-static modeling of an electrostatically actuated diaphragm compressor that could be employed in a miniature scale refrigeration system. The compressor consists of a flexible circular diaphragm clamped at its circumference. A conformal chamber encloses the diaphragm completely. The membrane and the chamber surfaces are coated with metallic electrodes. A potential difference applied between the diaphragm and the chamber pulls the diaphragm towards the chamber surface progressively from the outer circumference towards the center. This zipping actuation reduces the volume available to the refrigerant gas, thereby increasing its pressure. A segmentation technique is proposed for analysis of the compressor by which the domain is divided into multiple segments for each of which the forces acting on the diaphragm are estimated. The pull-down voltage to completely zip each individual segment is thus obtained. The required voltage for obtaining a specific pressure rise in the chamber can thus be determined. Predictions from the model compare well with other simulation results from the literature, as well as to experimental measurements of the diaphragm displacement and chamber pressure rise in a custom-built setup.
\end{abstract}

PACS classification codes: $07.10 . \mathrm{Cm}, 41.20 . \mathrm{Cv}$

Submitted to: Journal of Micromechanics and Microengineering

\section{INTRODUCTION}

The number of transistors on an electronic chip have been doubling approximately every 18-24 months, according to what is popularly referred to as Moore's law [1]. It has been predicted that the heat dissipation from a single chip package will rise to $200 \mathrm{~W}$ in 2008 for high-performance systems with local heat fluxes in the range of 40-60 W/ $\mathrm{cm}^{2}$ [2]. Traditional electronics cooling approaches such as forced convective air cooling using conventional heat sinks are soon expected to reach their limits for meeting the dissipation needs of emerging high-performance electronics systems [3]. Alternative electronics cooling approaches include heat pipes, liquid immersion, jet impingement and sprays, microchannel heat sinks, thermoelectric cooling, and refrigeration [4]. The feasibility of using a miniature vapor compression refrigeration system for cooling microprocessors was demonstrated by Cremaschi et al. [5]. The authors concluded that efficient and reliable mini- and micro-compressors are essential in order to achieve energy efficiencies that would render refrigeration systems competitive with other electronics cooling technologies. Trutassanawin et al. [6] experimentally tested a small-scale refrigeration system consisting of a commercially available miniature-scale compressor, a microchannel condenser and a cold plate evaporator. The system achieved a maximum cooling capacity of $226 \mathrm{~W}$ while maintaining the maximum $\mathrm{CPU}$ temperature at $53^{\circ} \mathrm{C}$. The overall system performance was found to strongly depend on the compressor efficiency and it was recommended that a new compressor design targeted specifically at electronics cooling applications would be needed to improve the system performance. The novel compressor would need to fit within a $45 \mathrm{~mm}$ height (1-U rack), be able to support a cooling capacity of $200 \mathrm{~W}$, and be reliable.

\footnotetext{
† Corresponding author. Email: groll@purdue.edu
} 


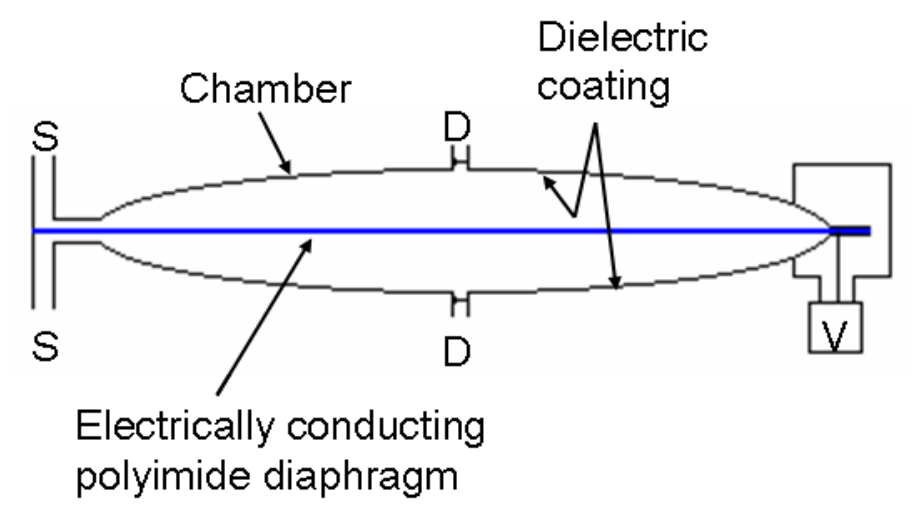

$$
\begin{aligned}
& S \text { - Suction port } \\
& D-\text { Discharge port and valve } \\
& \text { V-DC voltage power supply }
\end{aligned}
$$

Figure 1. Schematic representation of a diaphragm compressor.

An electrostatically actuated diaphragm compressor offers promise for this application because of its potential for high efficiency, compactness and scalability. The diaphragm compressor, schematically represented in Figure 1, consists of a flexible circular diaphragm clamped at its circumference. Two identical halves of a conformal chamber enclose the diaphragm completely. Gas is admitted into the chamber through the suction ports while the discharge valves control discharge flow and pressure rise. Metallic electrode layers are deposited on the diaphragm and on the chamber surfaces and dielectric layers are deposited on the top of the metallic electrodes to prevent electrical shorting when the diaphragm touches the chamber surface. The operation of the diaphragm compressor is illustrated in Figure 2. A DC voltage is applied between the diaphragm and one of the chamber halves that pulls in the diaphragm towards that chamber half because of an electrostatic attraction force. The magnitude of this force is inversely proportional to the square of the distance between the two electrodes (the chamber surface and the diaphragm). The diaphragm motion towards the chamber surface is initiated near its circumference due to the presence of the highest electrostatic force in this region. As the diaphragm is pulled in, the distance between the electrodes progressively decreases and more of the diaphragm is pulled towards the chamber surface. This self-sustaining pulling of the diaphragm is termed "zipping," which is initiated at the circumference and continues towards the center. This action reduces the volume available to the refrigerant gas in the chamber, thereby increasing its pressure. The discharge valve opens when the gas pressure reaches the design discharge pressure and the pressurized gas flows out of the chamber accompanied by further zipping of the diaphragm. At the end of the compression stroke, the polarity of the applied voltage differential is reversed and the compression cycle is continued in the reverse direction.

In the next section, different simulation models for electrostatic actuation and compression in the literature are reviewed and compared. 


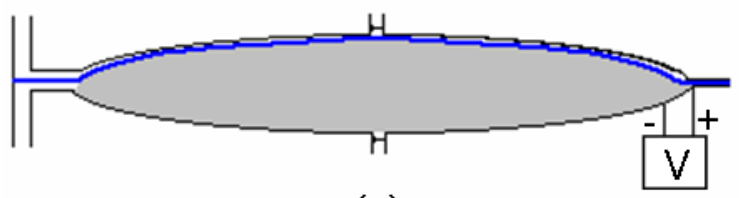

(a)

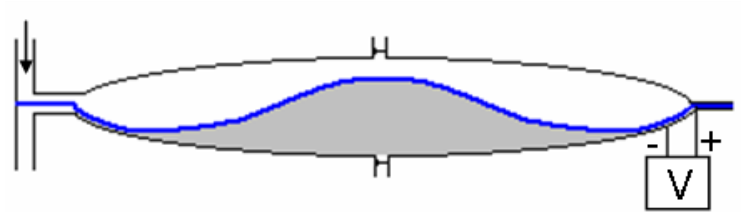

(b)

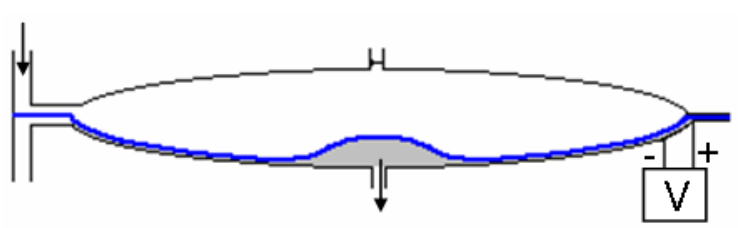

(c)

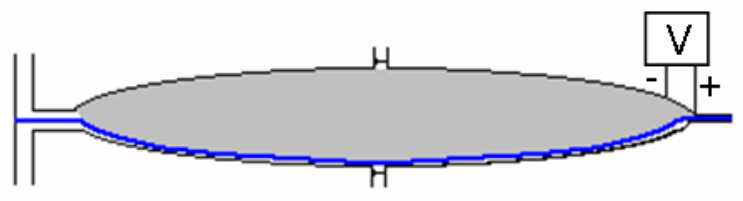

(d)

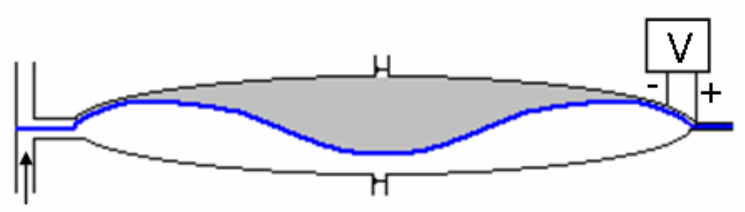

(e)

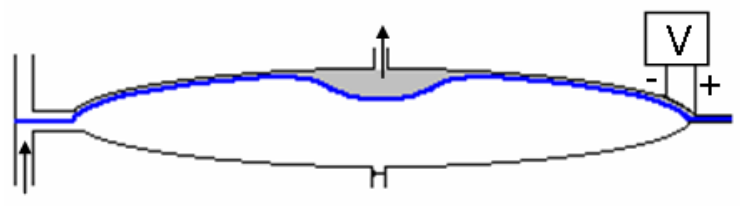

(f)

Figure 2. Step-by-step operation of diaphragm compressor.

\section{LITERATURE REVIEW}

Electrostatically actuated capacitive-type elastic systems are widely used in the design of micro- and nanoelectromechanical systems. The intrinsically unstable inverse square relationship between the applied DC voltage and the gap between the two electrodes resulting in a "pull-in" has been investigated in several theoretical and experimental studies, some of which are reviewed by Pelesko and Chen [7]. Analytical and numerical models for predicting the pull-in voltage for different elastic microstructure configurations 
(cantilever beam, clamped diaphragm, etc.) have also been developed [8,9]. These studies provide good insight into the electrostatic zipping phenomenon and form a basis for the diaphragm compressor analysis.

The feasibility of using electrostatic actuation for pumping a fluid (liquid or gas) has been studied by several researchers. Cabuz et al. [10,11] proposed a valveless dual-diaphragm pump, which consists of a conformal pumping chamber and two electrostatically actuated structured diaphragms. Pumping of the fluid was achieved without the need for suction/discharge valves by means of holes in the two diaphragms which were non-coincident to each other as well as to the suction and discharge ports. The pump provided a maximum flow rate of $30 \mathrm{ml} / \mathrm{min}$ at a pressure rise of $2 \mathrm{kPa}$, and had a power consumption of $8 \mathrm{~mW}$. An array of $2 \times 3 \times 2$ pumps with dimensions of $4.5 \times 3.5 \times 0.4 \mathrm{~cm}^{3}$ was shown to pump $230 \mathrm{ml} / \mathrm{min}$ of air at an actuation voltage of $160 \mathrm{~V}$.

Athavale et al. [12] proposed a bidirectional diaphragm pump based on electrostatic actuation for pumping gases at large flow rates. The pump consisted of two chambers with one inlet and two outlets, which were controlled independently. The pump was modeled using coupled transient computational flow simulations wherein separate solvers were developed for elastic, electrostatic and fluid flow processes and coupled to each other. A contact model was developed to simulate diaphragm contact with the electrodes. It was observed that the electrostatic forces were the highest at the outer edges and the contact was initiated at this location. The model predicted the actuation time and fluid flow rate for a given voltage. Effects of change in chamber configuration, electrode shape, diaphragm thickness, and material properties were also considered. An array of pumps that could produce pumping rates of air greater than $10 \mathrm{l} / \mathrm{min}$ was proposed.

Zengerle et al. [13] theoretically and experimentally investigated a bidirectional silicon micropump. It consisted of an electrostatically actuated diaphragm and two passive check valves. The micropump operated in the forward direction at low actuation frequencies and in the reverse direction at higher frequencies. The diaphragm pump had outer dimensions of $7 \times 7 \times 2 \mathrm{~mm}^{3}$ and achieved a maximum flow rate of $0.85 \mathrm{ml} / \mathrm{min}$ and a maximum hydrostatic back pressure of $31 \mathrm{kPa}$ at a supply voltage of $200 \mathrm{~V}$.

While these researchers [10 - 13] investigated the ability of electrostatic actuation to pump fluids, Shannon et al. [14] developed an electrostatically actuated diaphragm compressor for pressurizing refrigerant R134a vapor as part of a miniature cooler circuit designed for cooling of military personnel in hot environments. Each cooler circuit was designed to provide $3 \mathrm{~W}$ of cooling. The compressor was modeled using a lumped capacitance method where a force balance was made on the diaphragm to estimate the required actuation voltage. A donut-shaped chamber was recommended in which the chamber surface almost touched the diaphragm at the center. The shape of the chamber was optimized to reduce the pull-down voltage, to smooth the diaphragm profile during dynamic operation, and to limit the strain in the membrane at full closure. The required pull-down voltage was said to drop to $40 \mathrm{~V}$ from $770 \mathrm{~V}$ upon use of the donut-shaped chamber relative to the dome-shape, but this claim was not substantiated with experimental or modeling evidence.

Saif et al. [15] proposed an analytical model for an electrostatic membrane actuator for micropumps. The equilibrium position of the diaphragm was computed by minimizing the total energy of the membrane, which consisted of electrostatic and elastic internal energy. At equilibrium, the parallel-plate capacitive energy between the chamber and the membrane is the sum of the strain energy of the membrane and the pressure energy of the fluid. This energy balance was used for estimating the pull-down voltage. It was observed that for a given applied voltage, the pressure increased almost inversely with the thickness of the dielectric between the diaphragm and the chamber surface. Saif et al. also emphasized that dielectric breakdown may be a limiting factor for the maximum attainable pressure rather than the mechanical strength of the diaphragm material.

Table 1 summarizes the main details of the studies discussed above. Based on this summary, it is noted that a comprehensive diaphragm compressor model that calculates both the pressure rise and the volume flow 
rate of refrigerant vapor is not yet available. A lumped force balance is first developed in the next section based on approaches suggested in the literature, and it is shown that this approach is inadequate for representing all the key physical mechanisms that come into play in the compressor.

Table 1. Summary of different electrostatic pumping devices/models.

\begin{tabular}{|c|c|c|c|c|c|}
\hline & $\begin{array}{c}\text { Cabuz et al. } \\
{[10]}\end{array}$ & $\begin{array}{c}\text { Athavale et al. } \\
{[12]}\end{array}$ & $\begin{array}{c}\text { Zengerle et al. } \\
{[13]}\end{array}$ & $\begin{array}{c}\text { Shannon et al. } \\
{[14]}\end{array}$ & Saif et al. [15] \\
\hline Model type & Not specified & CFD & Theoretical & $\begin{array}{c}\text { Lumped force } \\
\text { balance }\end{array}$ & $\begin{array}{c}\text { Lumped } \\
\text { energy balance }\end{array}$ \\
\hline $\begin{array}{c}\text { Model details } \\
\text { provided? }\end{array}$ & No & No & Yes & No & Yes \\
\hline $\begin{array}{c}\text { Working } \\
\text { prototype }\end{array}$ & Yes & Yes & Yes & No & No \\
\hline Working fluid & Air & Air & Not specified & R134a & Not specified \\
\hline $\begin{array}{c}\text { Pressure rise } \\
\text { (kPa) }\end{array}$ & 2 & 0.7 & 31 & 750 & 6 \\
\hline $\begin{array}{c}\text { Volume flow } \\
\text { rate (ml/min) }\end{array}$ & 230 & Not specified & 0.85 & Not specified & Not specified \\
\hline $\begin{array}{c}\text { Required } \\
\text { voltage (V) }\end{array}$ & 160 & 50 & 200 & 40 & 250 \\
\hline
\end{tabular}

\section{LUMPED FORCE BALANCE AND NEED FOR SEGMENTATION}

The forces acting on the diaphragm are as follows: an electrostatic force imposed by the voltage differential between the diaphragm and the chamber surface, an elastic force caused by the stretching of the diaphragm, and a gas force resulting from the increase in differential pressure of the compressed gas (Figure 3). A maximum chamber depth of $y_{\max }$ is assumed, while the deflection of the diaphragm from the equilibrium position is $y$. The elastic force induced in the diaphragm because of this deflection is calculated as [16]:

$$
F_{e l}=K \cdot A \cdot y
$$

where $A$ is the diaphragm surface area, $K$ is a hypothetical diaphragm elastic stiffness and $y$ is the deflection at the center of diaphragm. The elastic stiffness is calculated as [17]:

$$
K=\frac{16 \cdot E}{3 \cdot\left(1-v^{2}\right)} \cdot \frac{w^{3}}{R_{\max }^{4}} \cdot(1+\alpha)
$$

In this case $R_{\max }, w, E$ and $v$ are the diaphragm radius, thickness, elastic modulus and Poisson's ratio, respectively. The diaphragm tension parameter $\alpha$ is calculated as:

$$
\alpha_{i}=0.817 \cdot\left(1-v^{2}\right) \cdot \frac{\sigma_{r e s}}{E} \cdot\left(\frac{R_{i}}{w}\right)^{2}
$$

where $\sigma_{\text {res }}$ is the initial (or residual) stress in the diaphragm.

The pressure rise in the chamber is calculated as:

$$
P_{\text {gas }}=P_{\text {suction }} \cdot\left[\frac{\text { Vol }_{\text {chamber }}}{\text { Vol }_{\text {gas }}}\right]^{\gamma}
$$


where $\gamma$ is the polytropic compression index. The volume of the chamber $\left(V_{o l} l_{\text {chamber }}\right)$ is a function of the chamber profile, maximum chamber depth $\left(y_{\max }\right)$ and chamber radius. The volume of the gas $\left(\operatorname{Vol}_{\text {gas }}\right)$ is calculated as a function of the diaphragm deflection and the chamber volume. The force exerted by the pressurized gas on the diaphragm is:

$$
F_{\text {gas }}=\left(P_{\text {gas }}-P_{\text {suction }}\right) \cdot A
$$

The force balance on the diaphragm is given as:

$$
F_{e s}=F_{e l}+F_{\text {gas }}
$$

An electrostatic force on the diaphragm is generated by the application of a voltage differential between the diaphragm and the chamber surface. For a capacitor whose plates are flat and parallel (in this case, the diaphragm and chamber surface) the electrostatic force for an applied voltage differential of $V$ can be estimated [14] as:

$$
F_{e s}=\frac{\varepsilon_{0}}{2} \frac{V^{2} \cdot A}{\left(\frac{t_{d}}{k_{d}}+\left(y_{\max }-y\right)\right)^{2}}
$$

where $\varepsilon_{0}$ is the permittivity of vacuum. The thickness of the dielectric layer on the chamber surface and its dielectric constant are given by $t_{d}$ and $k_{d}$, respectively.

Rearranging equation (7) and substituting equations (1) through (6), the required pull-down voltage is given as:

$$
\begin{aligned}
& V_{P}=\sqrt{\frac{2}{\varepsilon_{0}} \frac{\left(P_{\text {gas }}-P_{\text {suction }}\right) \cdot A+K \cdot y}{A}} \cdot\left(\frac{t_{d}}{k_{d}}+\left(y_{\max }-y\right)\right)
\end{aligned}
$$

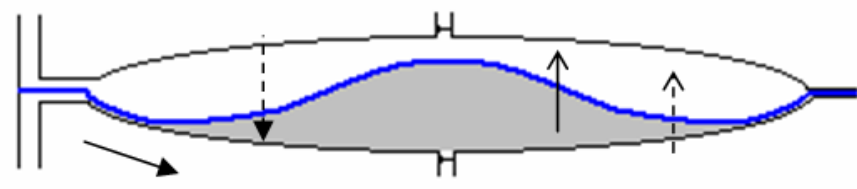

$$
\begin{aligned}
& \longrightarrow \text { Diaphragm } \square \text { Compressed gas } \\
& \longrightarrow \text { Direction of progressive zipping } \\
& \text {----- Direction of electrostatic force } \\
& \longrightarrow \text { Direction of elastic force } \\
& \text {----- Direction of gas force }
\end{aligned}
$$

Figure 3. Forces acting on the diaphragm.

The pull-down voltage $\left(V_{P}\right)$ calculated above is valid for a flat plate capacitor. The non-linear chamber profile is approximated as a parallel-plates capacitor as shown in Figure 4 (a). This approximation, however, does not consider the zipping actuation of the diaphragm described earlier, initiated from the circumference of the diaphragm inwards. The inability of the lumped model to simulate the zipping actuation of the diaphragm results in an inaccurate estimation of the electrostatic force and the pull-down 
voltage. Also, the lumped model does not consider the spring hardening effect [18] while calculating the elastic force on the diaphragm.

To overcome the shortcomings of the lumped capacitance model, a segmentation approach as described in Figure 4 (b) is proposed. The chamber profile is divided into a number of radial segments. The forces on the diaphragm and the force balance are calculated for each segment. In addition, the spring hardening effect of the diaphragm is accounted for in the new model. The electrostatic force is then calculated on a sufficiently large number of parallel-plate capacitor segments that faithfully represent the chamber geometry.

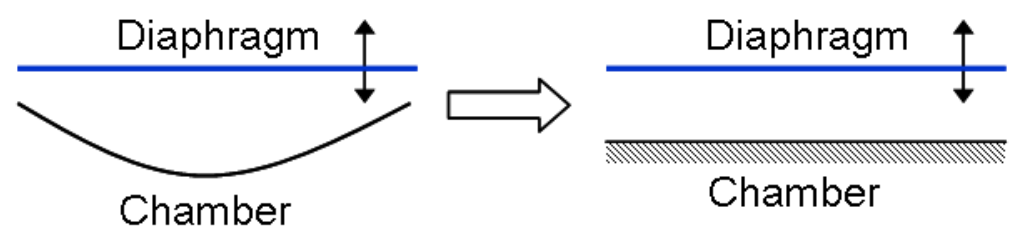

(a)

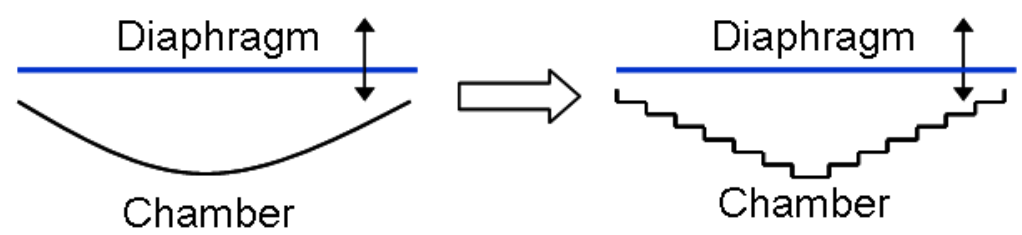

(b)

Figure 4. Linearization of the chamber surface (a) as a parallel-plates arrangement, and (b) by the proposed segmentation method.

\section{SEGMENTATION-BASED COMPRESSOR MODEL}

Consider a generic chamber shape represented in dimensionless form as:

$$
\frac{y}{y_{\max }}=\sum_{x=0}^{z} a_{x} \cdot\left(\frac{R}{R_{\max }}\right)^{x}
$$

where $\mathrm{y}$ is the depth at radius $R$ with $0 \leq y \leq y_{\max }$ and $0 \leq R \leq R_{\max }$. Coefficients for the terms of the polynomial are given by $a_{x}$.

A schematic representation of the segmentation is shown in Figure 5. The segmentation starts from the circumference such that the outer radius of the first segment is the same as the maximum radius of the chamber $\left(R_{1}=R_{\max }\right)$ and the inner radius of the last segment is zero $\left(R_{N+1}=0\right)$. The entire chamber radius is divided into $N$ equal radial segments (Figure 5 (a)) such that the radial width of all segments is equal:

$$
\begin{aligned}
& \text { For } i=1 \text { to } N+1: \\
& R_{i+1}=R_{\max } \cdot(1-i / N)
\end{aligned}
$$

The net area of each segment is calculated as:

$$
\begin{gathered}
\text { For } i=1 \text { to } N+1: \\
A_{i}=\pi \cdot R_{i}^{2}
\end{gathered}
$$


Following the radial segmentation, the vertical endpoints of the segment radii are calculated as shown in Figure 5 (a). This involves using the equation for the chamber profile and calculating the depth $y$ (or height) for any radius $r$ at given $R_{\max }$ and $y_{\max }$. In the next step, the actual segment heights are calculated by averaging the vertical segment end points as shown in Figure $5(b)$ :

$$
\begin{aligned}
\text { For } i=1 \text { to } N+1: \\
y_{\text {seg }, i}=\frac{y_{i}+y_{i+1}}{2}
\end{aligned}
$$

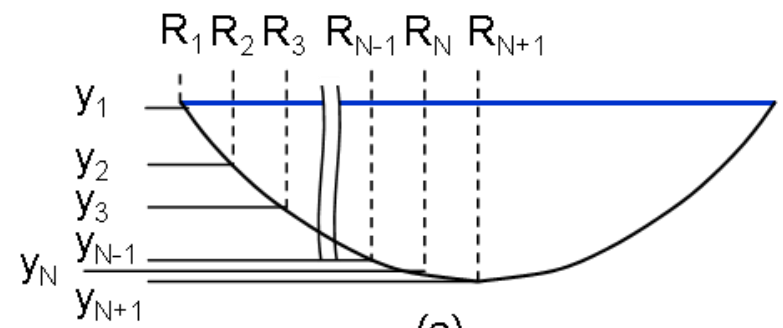

(a)

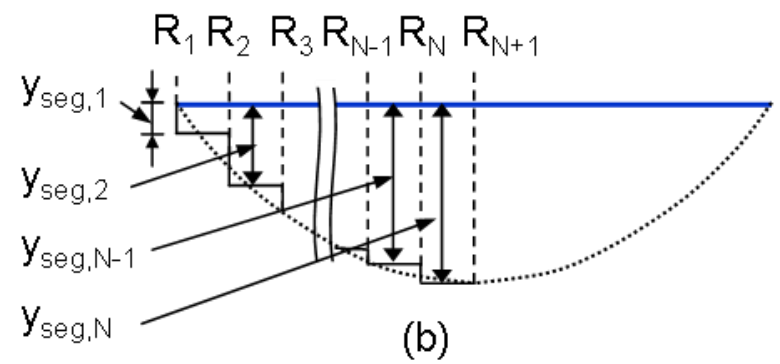

Figure 5. Segmentation of the chamber geometry for generating $N$ segments in steps (a) and (b).

Thus, $y_{\text {seg }}$ is the average height of each segment. By using a large number of segments, the error in this averaging is asymptotically minimized. The quasi-static segment-wise diaphragm zipping actuation is illustrated in Figure 6. The calculations start at the circumference (at segment \# 1) and proceed towards the center. The forces on the diaphragm are evaluated at each segment to calculate the required pull-down voltage for that segment, proceeding from the circumference towards the center. 


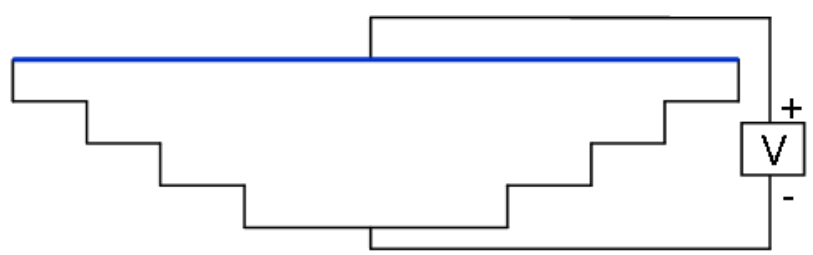

(a)

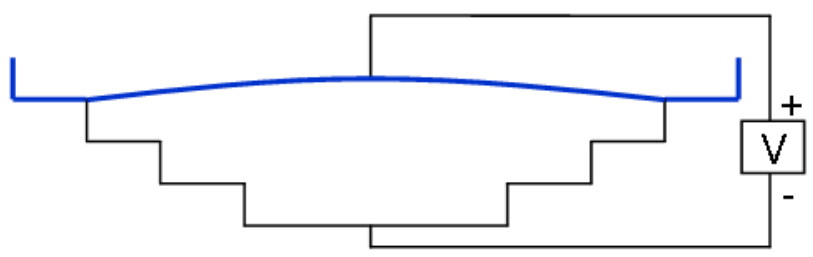

(b)

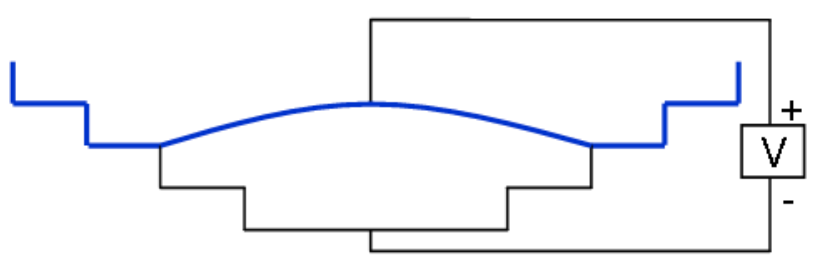

(c)

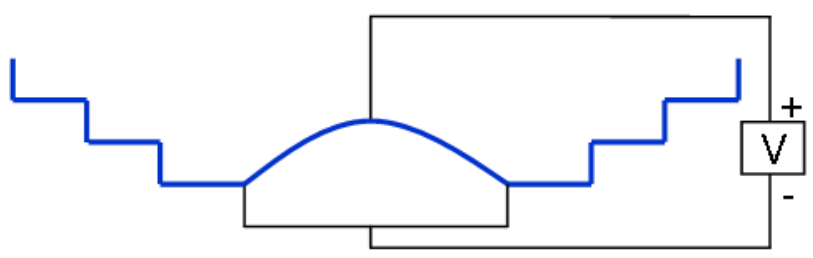

(d)

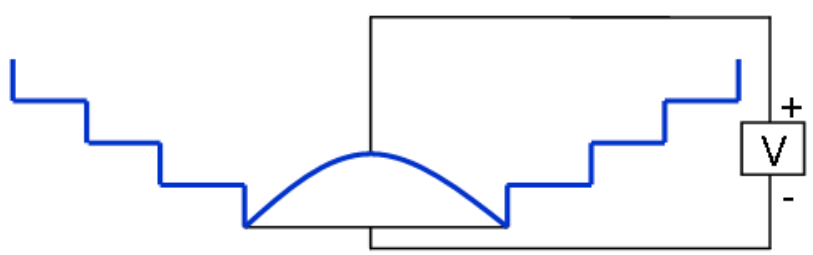

(e)

Figure 6. Quasi-static simulation of the zipping actuation of diaphragm in steps (a) through (e)

The following simplifications and assumptions are made while modeling the forces:

- Only one half of the chamber is considered. The diaphragm is assumed to be in an equilibrium position at the start of each compression stroke (Figure 6 (a)).

- Since the chamber depth is very small compared to its diameter, the forces on the diaphragm are assumed to always act perpendicular to the diaphragm surface.

- The deflection of the diaphragm is assumed to be a quasi-static process. i.e., the diaphragm moves in infinitesimally small steps and the dynamic effects due to its motion (such as inertia force, damping force, etc.) are not considered in this analysis.

- The discharge valve is assumed to open as soon as the gas pressure equals the discharge pressure. Once the discharge valve has opened, the pressure inside the chamber is assumed to remain constant. 
- Once the diaphragm touches the chamber surface, it is assumed to stay in contact with the latter for the rest of the compression cycle (Figure 6(b) - (e)). Any gas that may be trapped between the zipped portion of the diaphragm and the cavity wall is neglected.

- The effect of friction between the zipped portion of the diaphragm and the chamber surface on the force balance is neglected, $i$. e., frictionless contact between the chamber surface and the membrane is assumed.

- A clearance volume of $1 \%$ is assumed in the compression chamber; that is, once the volume of the compressed gas decreases to $1 \%$ of the total chamber volume, the force balance calculations are stopped.

- Heat transfer across the diaphragm and the chamber are neglected. Our calculations indicate that the temperature rise in the chamber for a $30 \mathrm{kPa}$ pressure rise is approximately $2 \mathrm{~K}$, which would lead to negligible thermal interactions.

For each segment $i(1 \leq i \leq N)$, the elastic force on the diaphragm is calculated by modifying Equations (1) through (3) for the segmented structure as:

$$
\begin{aligned}
& \text { For } i=1 \text { to } N: \\
& \qquad \begin{array}{c}
\alpha_{i}=0.817 \cdot\left(1-v^{2}\right) \cdot \frac{\sigma_{r e s}+\sigma_{a d d, i-1}}{E} \cdot\left(\frac{R_{i}}{w}\right)^{2} \\
K_{i}=\frac{16 \cdot E}{3 \cdot\left(1-v^{2}\right)} \cdot \frac{w^{3}}{R_{i}^{4}} \cdot\left(1+\alpha_{i}\right) \quad\left(R_{i} \neq 0\right) \\
F_{\text {el }, i}=A_{i} \cdot K_{i} \cdot y_{\text {seg }, i}
\end{array}
\end{aligned}
$$

The stiffness coefficient of the diaphragm $K$ is calculated for each segment. It takes into account the spring hardening effect by using an additional stress term $\left(\sigma_{\text {add }}\right)$ for calculating the tension parameter $\alpha$ for each segment that reflects the strain on the diaphragm.

The gas pressure force on the diaphragm for each segment is calculated by modifying Equation (4) for the segmented domain as:

$$
\begin{aligned}
& \text { For } i=1 \text { to } N: \\
& \qquad \begin{array}{l}
\operatorname{Vol}_{\text {seg }, i}=A_{\text {seg }, i} \cdot y_{\text {seg }, i} \\
P_{\text {seg }, i}=P_{\text {suction }} \cdot\left[\frac{V o l_{\text {chamber }}}{V o l_{\text {chamber }}-V o 1_{\text {seg }, i}}\right] \\
F_{\text {gas }, i}=A_{\text {seg }, i} \cdot\left(P_{\text {seg }, i}-P_{\text {suction }}\right)
\end{array}
\end{aligned}
$$

The force balance for each segment can now be written as:

$$
\begin{aligned}
& \text { For } i=1 \text { to } N: \\
& F_{e s, i}=F_{e l, i}+F_{g a s, i}
\end{aligned}
$$

Based on this force balance, the electrostatic force on the diaphragm is calculated for each segment. Rewriting Equation (8) for the segmented domain gives the required segment pull-down voltage as:

For $i=1$ to $N$ :

$$
V_{i}=\sqrt{\frac{2}{\varepsilon_{0}} \cdot \frac{F_{e l, i}+F_{g a s, i}}{\sum_{j=i}^{N} \frac{\left(A_{j}-A_{j+1}\right)}{\left(t_{d} / k_{d}+y_{s e g, j}-y_{s e g, i-1}\right)^{2}}}}
$$


Equation (16) provides the required pull-down voltage for each segment. The areas and heights of the segments are estimated based on the segmentation described using Equations (9) through (12). The elastic and gas forces for each segment are calculated using Equations (13) and (14), respectively. The segment pull-down voltage reflects the resistance of that diaphragm segment to pull-down. The operating voltage for the diaphragm compressor (the voltage that must be applied between the compressor electrodes), however, is the maximum pull-down voltage over all of the segments:

$$
\begin{gathered}
\text { For } i=1 \text { to } N: \\
V_{\text {oper }}=\max \left(V_{i}\right)
\end{gathered}
$$

The segmentation-based simulation procedure is summarized as:

$$
\begin{aligned}
& \text { For } i=1 \text { to } N \text { : } \\
& \text { 1. Segmentation } \\
& \text { 2. Elastic and gas forces } \\
& \text { 3. Force balance } F_{e s, i}=F_{e l, i}+F_{g a s, i} \\
& \text { 4. Segment pull-down voltage } V_{i} \\
& \text { 5. Operating voltage } V_{o p e r}=\max \left(V_{i}\right)
\end{aligned}
$$

The force balance calculations start at the circumference and proceed towards the center, corresponding to the zipping of the diaphragm being initiated at the circumference and propagating towards the center. This is a generic, physics-based, and quasi-static model that can be applied to any chamber profile.

\section{MODEL PREDICTIONS AND VALIDATION}

The capabilities of the segmentation-based diaphragm compressor model are demonstrated and predictions from the model validated against published results using the following parameters and with refrigerant R134a as the working fluid:

- Radius of diaphragm and chamber $R_{\max }=10 \mathrm{~mm}$

- Maximum depth of chamber $y_{\max }=100 \mu \mathrm{m}$

- Thickness of dielectric layer on chamber surface $t_{d}=1 \mu \mathrm{m}$

- Dielectric strength of dielectric layer $k_{d}=3.5$

- Diaphragm material: Metallized polyimide Kapton [19]

- Thickness $h=25 \mu \mathrm{m}$

- Elastic modulus $E=3.02 \mathrm{GPa}$

- Poisson's ratio $v=0.3$

- $\quad$ Suction pressure $=572.1 \mathrm{kPa}$

- Pressure rise $=30 \mathrm{kPa}$ (chosen based on the maximum pressure that the diaphragm can support for the given geometry and material before undergoing plastic deformation, as calculated in the Appendix)

The chamber shape is represented by the following $6^{\text {th }}$-order equation [10] to ensure a smooth profile and a small slope at the circumference, factors that are important to ensure initiation and progressive zipping:

$$
\begin{aligned}
\frac{y}{y_{\max }}=1 & -\left(\frac{R}{R_{\max }}\right)^{2}-0.1 \cdot\left(\frac{R}{R_{\max }}\right)^{3}+0.1 \cdot\left(\frac{R}{R_{\max }}\right)^{4} \\
& -0.1 \cdot\left(\frac{R}{R_{\max }}\right)^{5}+0.1 \cdot\left(\frac{R}{R_{\max }}\right)^{6}
\end{aligned}
$$


The domain is divided into $N$ segments and the segmented diaphragm compressor model is computed using MATLAB [20]. The pressure rise in the chamber as a function of non-dimensional radius is shown in Figure 7. The non-dimensional radius of the diaphragm is defined as the ratio of the segment radius to the maximum chamber radius as shown below:

$$
\begin{array}{r}
\text { For } i=1 \text { to } N: \\
R_{n d, i}=\frac{R_{i}}{R_{\max }}
\end{array}
$$

A non-dimensional radius ( $\left.R_{n d}\right)$ of 1 indicates the $1^{\text {st }}$ segment (at the circumference) while a value of 0 indicates the last segment (at the center). The calculations are not continued until the last segment, but instead, are stopped when the gas volume decreases to a clearance volume (dead volume) in the amount of $1 \%$ of the chamber volume; this corresponds to a non-dimensional radius of 0.3 . From Figure 7 it is seen that the gas pressure continues to rise as long as it is below the pre-set discharge pressure for which the discharge valve is designed. As this pressure is reached, the discharge valve opens and beyond this point, the pressure in the chamber remains constant for the remaining stroke of the diaphragm.

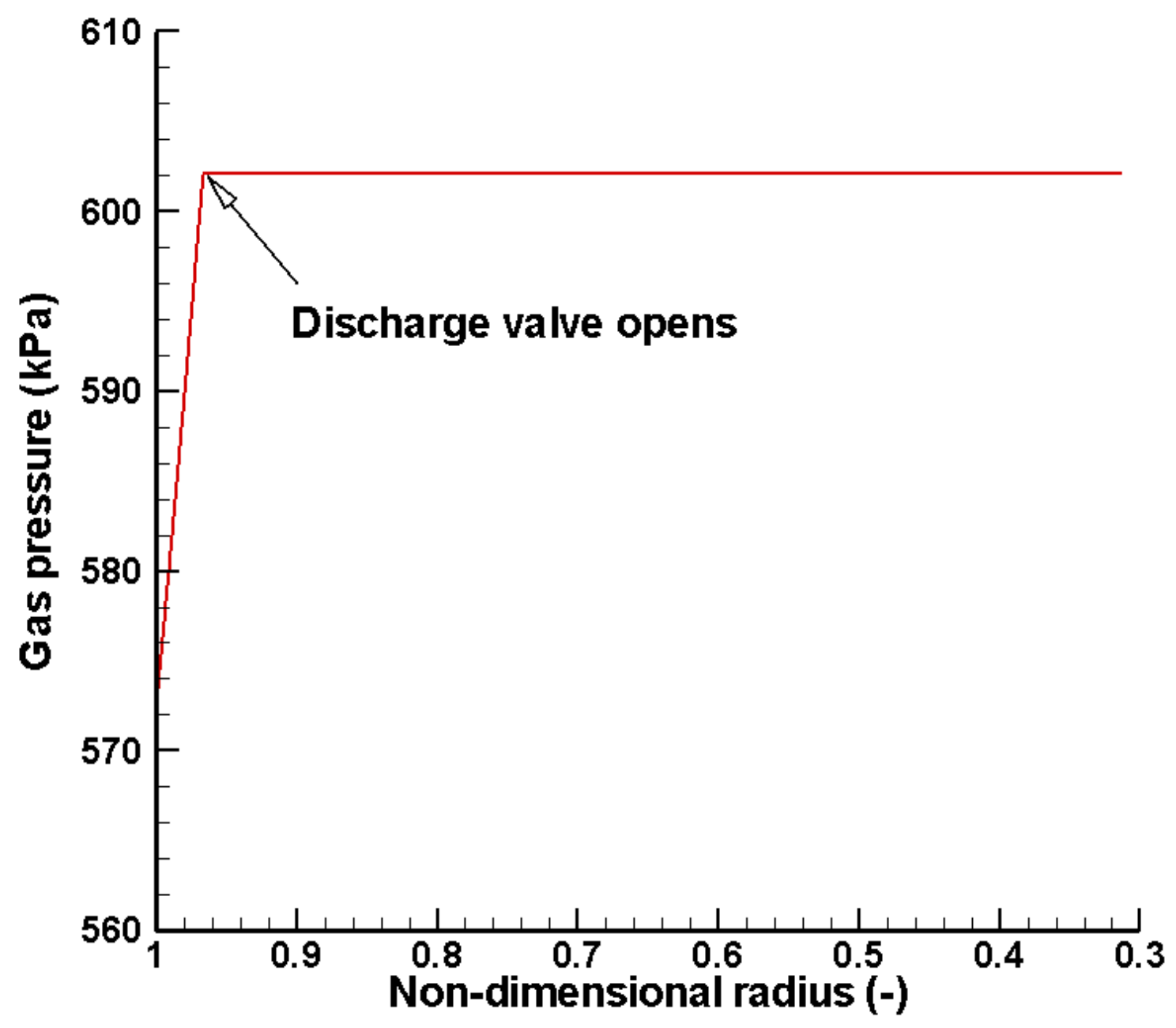

Figure 7. Gas pressure as a function of chamber non-dimensional radius. 
The forces on the diaphragm are shown in Figure 8 as a function of non-dimensional radius. The elastic force increases linearly as the diaphragm zips from the circumference to the center. This can be attributed to the spring-hardening effect of the diaphragm discussed earlier. As a greater portion of the diaphragm is zipped, the unzipped portion stiffens and needs a stronger force to deflect. The gas force increases corresponding to the increase in gas pressure. Once the discharge valve opens (and the gas pressure reaches a constant value), the gas force decreases due to the decrease in the area of the segments from the circumference to the center. The electrostatic force is the sum of the two forces for each segment.

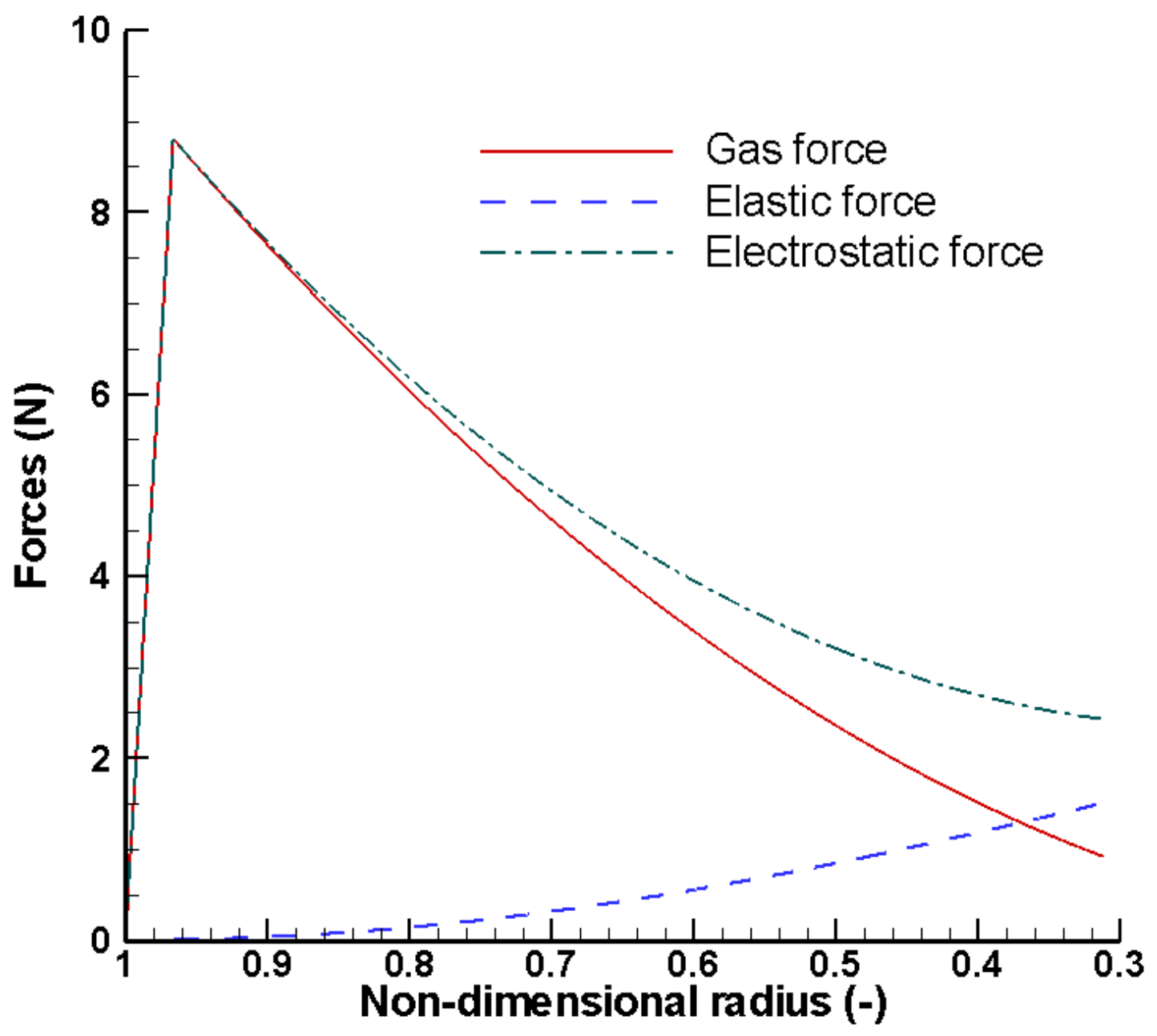

Figure 8. Variation of different forces on the diaphragm as a function of chamber non-dimensional radius.

The variation of the pull-down voltage with non-dimensional radius is shown in Figure 9. This curve follows a similar trend to that of the electrostatic force. Hence as the gas is pressurized inside the chamber, the required pull-down voltage for zipping the diaphragm from the circumference to the center first increases and then decreases once the discharge valve is opened. The maximum pull-down voltage for the chosen parameters is $402 \mathrm{~V}$. Thus, for pressurizing R134a vapor by $30 \mathrm{kPa}$ inside the given chamber, a DC voltage differential of $402 \mathrm{~V}$ is required across the diaphragm and the chamber. 


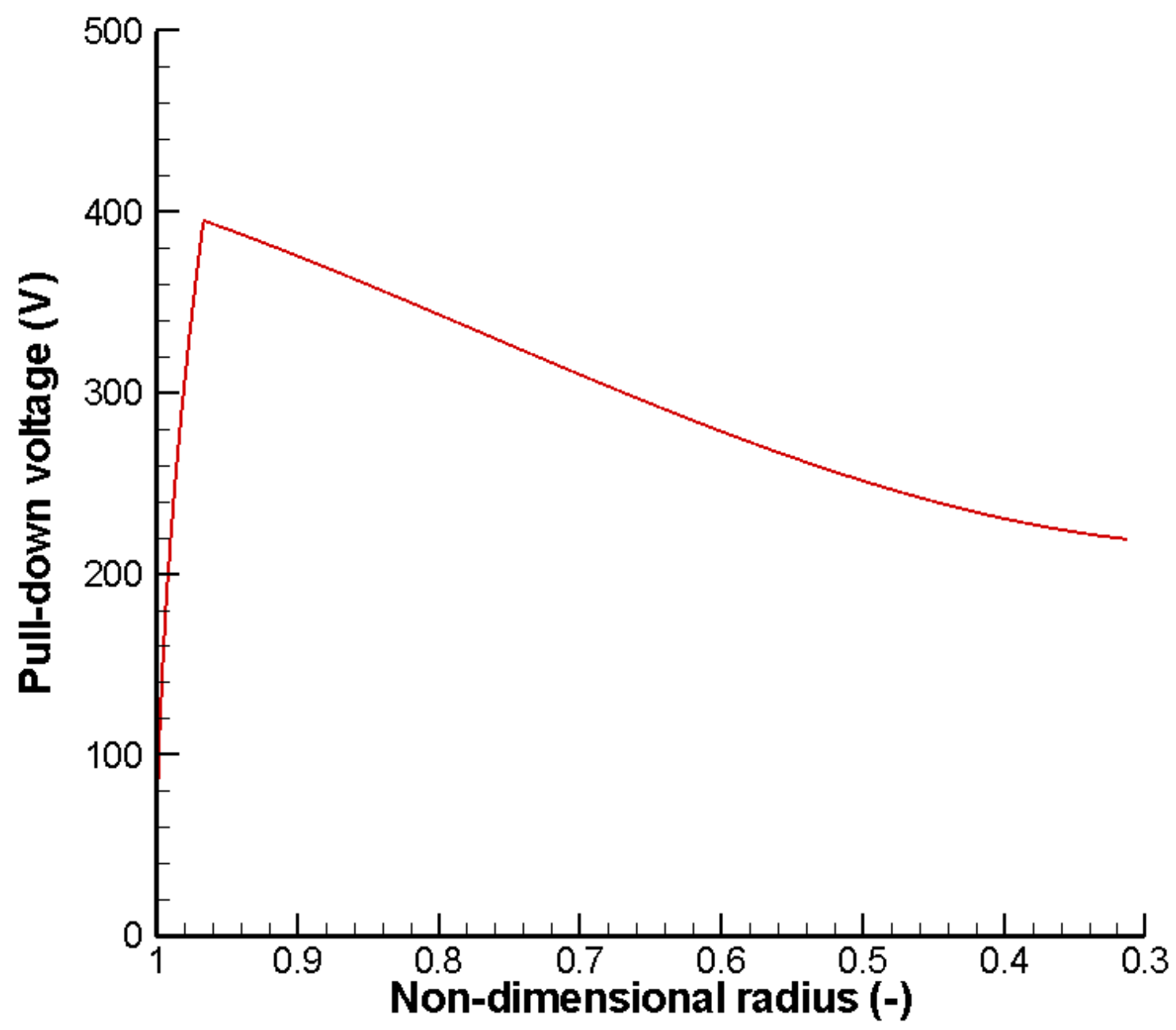

Figure 9. Variation of the pull-down voltage as a function of chamber non-dimensional radius.

Results from the segment-wise diaphragm compressor model developed here are compared with the energy balance-based simulation results of Saif et al. [15] for a dome-shaped diaphragm compressor with the parameters specified in (given in Table 2). Figure 10 presents the equilibrium pressure rise in the chamber as predicted by Saif et al. as well as predictions from the present model as a function of applied voltage. Predictions from the current model compare well with those of Saif et al. with a somewhat lower pressure rise predicted at higher voltages by the segmentation-based model. The present work calculates the changes in diaphragm strain, chamber pressure and electrostatic field progressively in a simulation of the advance of the contact front from the circumference to the center. Saif et al.'s energy-based model, on the other hand, used closed-form lumped integral equations for the estimation of these parameters. They are calculated at an equilibrium position, which does not take zipping of the diaphragm into account. Hence, the authors believe that the electrostatic force calculated by the current model is more accurate than that calculated using a lumped capacitance method. 
Table 2. Parameters from the model of Saif et al. [15].

\begin{tabular}{ll}
\hline Chamber radius $R_{\max }$ & $5 \mathrm{~mm}$ \\
\hline Maximum chamber depth $y_{\max }$ & $100 \mu \mathrm{m}$ \\
\hline Dielectric thickness on chamber surface $t_{d}$ & $0.2 \mu \mathrm{m}$ \\
Dielectric constant $k_{d}$ & 3.0 \\
\hline Diaphragm thickness $h$ & $5 \mu \mathrm{m}$ \\
\hline Diaphragm elastic modulus $E$ & $2.714 \mathrm{GPa}$ \\
Poisson's ratio $v$ & 0.3 \\
\hline Compression index $n$ & 1.0 (Isothermal) \\
\hline Suction pressure $P_{\text {suction }}$ & 8 bars \\
\hline
\end{tabular}

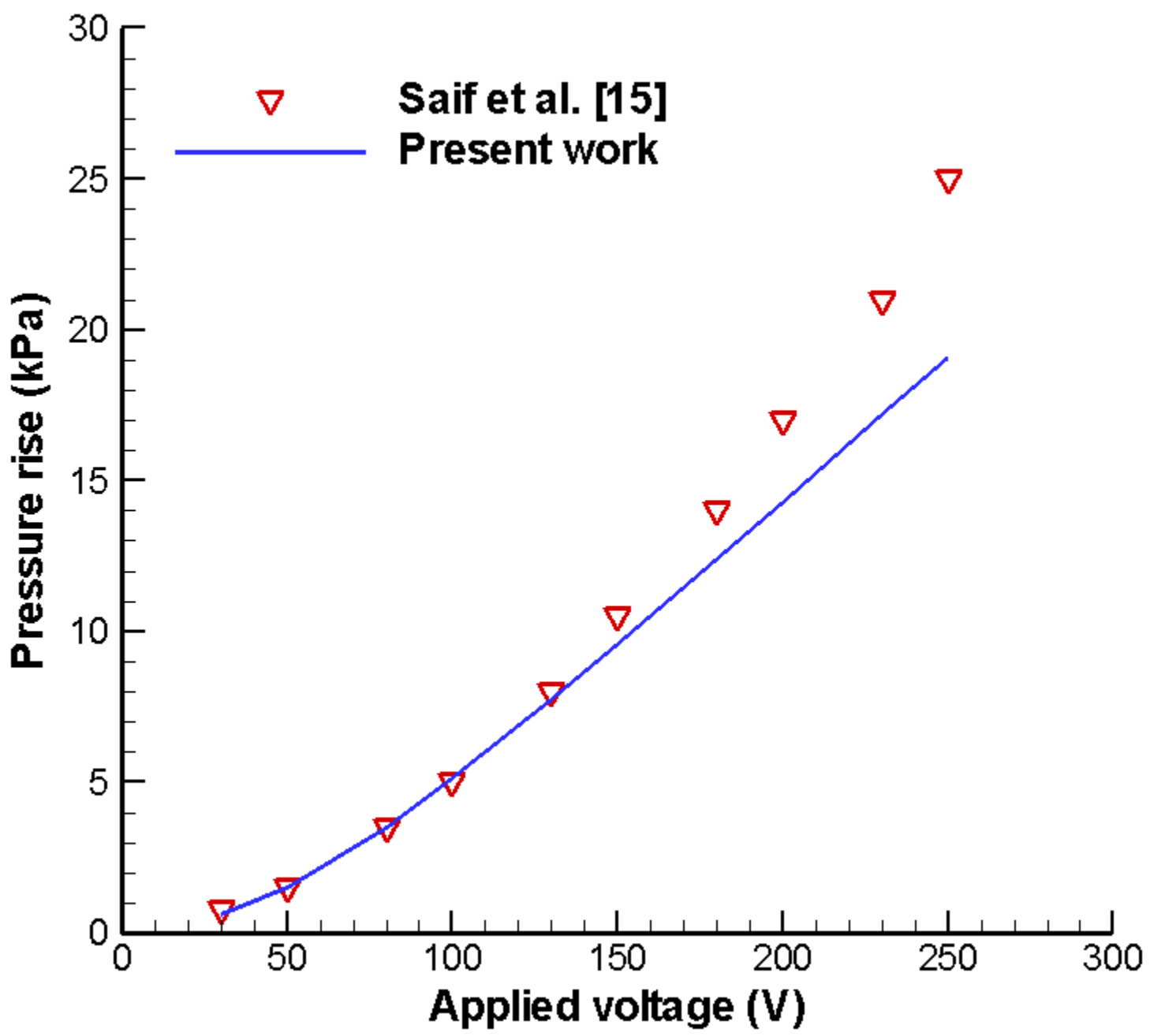

Figure 10. Comparison of the segmentation model results from the present work to those from the lumped energy model of Saif et al. [15]. 


\section{EXPERIMENTAL ANALYSIS}

A simplified diaphragm actuation test setup is designed and fabricated according to the principle illustrated in Figure 11. A similar setup was used by Shannon et al. [14] for conducting hold-off pressure tests. The present setup, however, is specifically designed to achieve a pressure rise in the chamber using electrostatic actuation. The diaphragm is electrostatically attracted to a flat metal electrode that has a hole in the center through which pressurized gas is supplied. The diaphragm bulges upwards in response to the nitrogen gas pressure (Figure 11 (a)). The gas in the chamber is then isolated from the supply line using a valve (Figure 11 (b)). A DC voltage differential is applied between the flat electrode and the diaphragm, which pulls the diaphragm towards the electrode. The resultant rise in the pressure of the gas is measured (Figure 11 (c)).

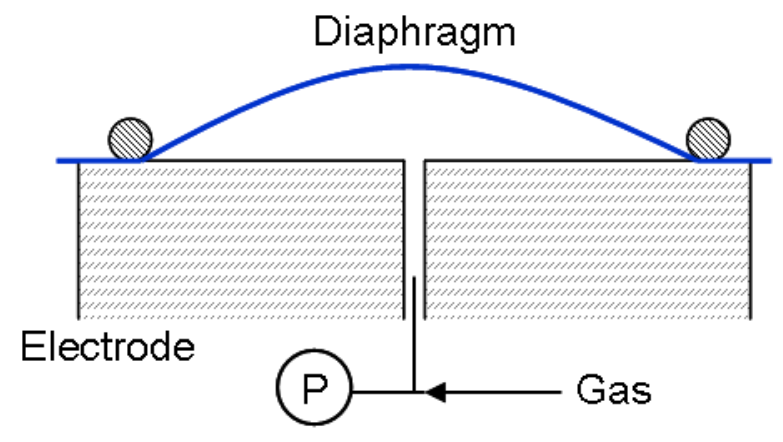

(a)

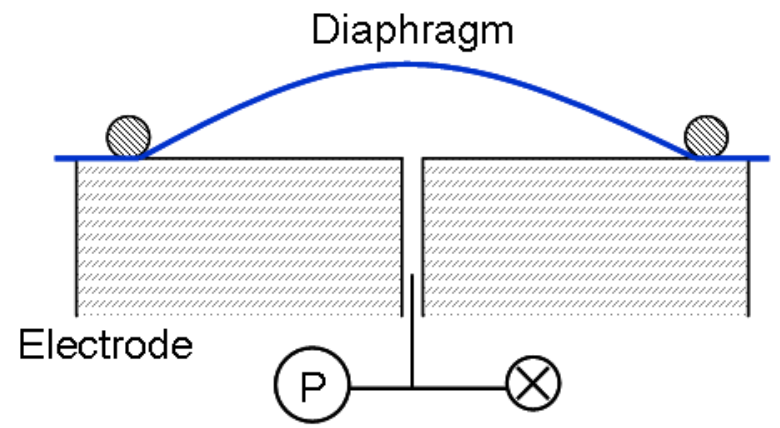

(b)

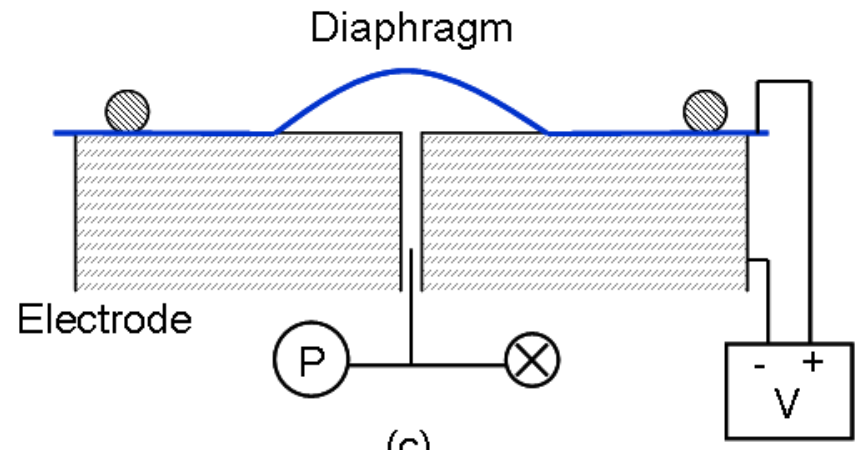

(c)

Figure 11. Principle of operation of the experimental setup: (a) Diaphragm inflated with gas, (b) chamber isolated using valve, and (c) DC voltage applied to zip the diaphragm. 
An exploded view of the experimental setup is shown in Figure 12. This setup uses a flat electrode, and obviates the complexities in machining the curved chamber surface previously discussed. A circular stainless steel electrode of $30.5 \mathrm{~mm}$ diameter serves as the flat electrode; a hole drilled in the center of this electrode admits gas into the chamber. The steel electrode is connected to the ground or the negative terminal of the voltage supply. The top surface of the steel electrode is coated with $11 \mu \mathrm{m}$ of Parylene $\mathrm{C}$ which serves as the dielectric layer. A plastic casing holds the steel electrode and also houses a copper ring used for supplying positive voltage to the diaphragm. A sealing ring prevents leakage from the chamber. A $25 \mu \mathrm{m}$ thick metallized Kapton sheet is used as the diaphragm. The diaphragm is held under tension using a plastic ring. The plastic top cover has two grooves for sealing rings. The inner and outer rings serve to press the diaphragm against the steel electrode and copper ring, respectively.

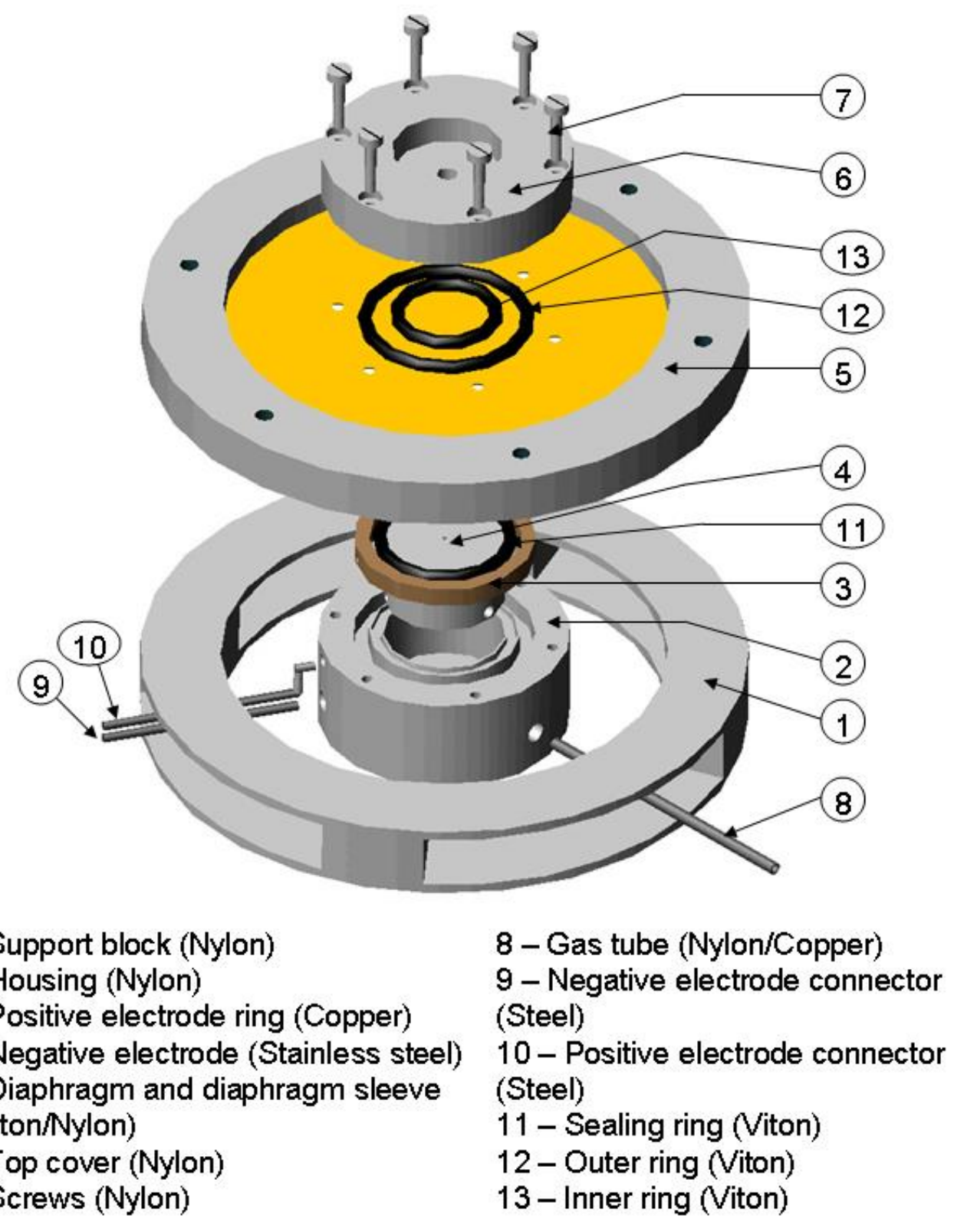

Figure 12. Exploded view of the experimental setup. 
The pressure in the system is measured using a low-range (50 inches of water column), high-accuracy ( $0.5 \%$ full scale, or $\pm 62 \mathrm{~Pa}$ ) differential pressure transducer. The diaphragm deflection $(\delta)$ is measured from the top using a laser displacement sensor (Keyence LK-G157) with a measurement uncertainty of $0.1 \mu \mathrm{m}$. The deflection reads zero for a flat diaphragm and positive values for a bulged diaphragm. Pure nitrogen gas is used for the experiments. One of the major differences between the diaphragm compressor described previously and the existing experimental setup is the chamber volume. For the actual compressor, the total chamber volume is always fixed (decided by the chamber radius and the maximum depth). In the experimental setup, on the other hand, the chamber volume is a function of the inlet gas pressure. The higher the inlet pressure, the greater is the diaphragm deflection $(\delta)$ and the larger the chamber volume. As an example, for an inlet pressure of $0.5 \mathrm{kPa}$, the diaphragm deflection is $82 \mu \mathrm{m}$ and the corresponding chamber volume is $20.3 \mathrm{~mm}^{3}$. If the inlet pressure is increased to $1 \mathrm{kPa}$, the deflection is now $146 \mu \mathrm{m}$ and the chamber volume is $36.4 \mathrm{~mm}^{3}$. The system dead volume (defined as the internal volume of the tubing) is estimated to be $26.3 \mathrm{~mm}^{3}$. This high dead volume limits the pressure rise that can be achieved with the setup. It is noted that the aim of the experiments is not to simulate a real compressor, but instead to serve as a tool for validating the segmentation model.

For a known gas pressure in the chamber, different voltages are applied to the system and the pressure rise and the change in deflection of the diaphragm recorded. A total of 35 data points were taken based on the test matrix shown in Table 3. Figure 13 shows the pressure rise in the chamber as function of the applied DC voltage for different inlet pressures. It is clear that as the voltage is increased, the pressure rise increases. However, at a certain voltage the diaphragm zips completely onto the stainless steel flat electrode and the pressure does not rise with further increase of voltage.

Table 3. Experimental test matrix.

\begin{tabular}{|c|c|c|c|c|c|c|}
\hline & \multicolumn{5}{|c|}{ Inlet pressure $(\mathrm{kPa})$} \\
\hline & & 0.5 & 0.75 & 1 & 1.25 & 1.5 \\
\hline \multirow{9}{*}{ 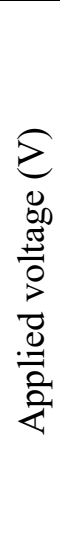 } & 300 & $X$ & $X$ & & & \\
\hline & 350 & $\mathrm{X}$ & $X$ & & & \\
\hline & 400 & $\mathrm{X}$ & $X$ & $X$ & $X$ & \\
\hline & 450 & $\mathrm{X}$ & $\mathrm{X}$ & $\mathrm{X}$ & $\mathrm{X}$ & $X$ \\
\hline & 500 & $X$ & $\mathrm{X}$ & $X$ & $X$ & $X$ \\
\hline & 550 & $\mathrm{X}$ & $X$ & $\mathrm{X}$ & $X$ & X \\
\hline & 600 & $X$ & $\mathrm{X}$ & $X$ & $X$ & $X$ \\
\hline & 650 & $\mathrm{X}$ & $X$ & $X$ & $X$ & $X$ \\
\hline & 700 & & & & $X$ & $X$ \\
\hline
\end{tabular}




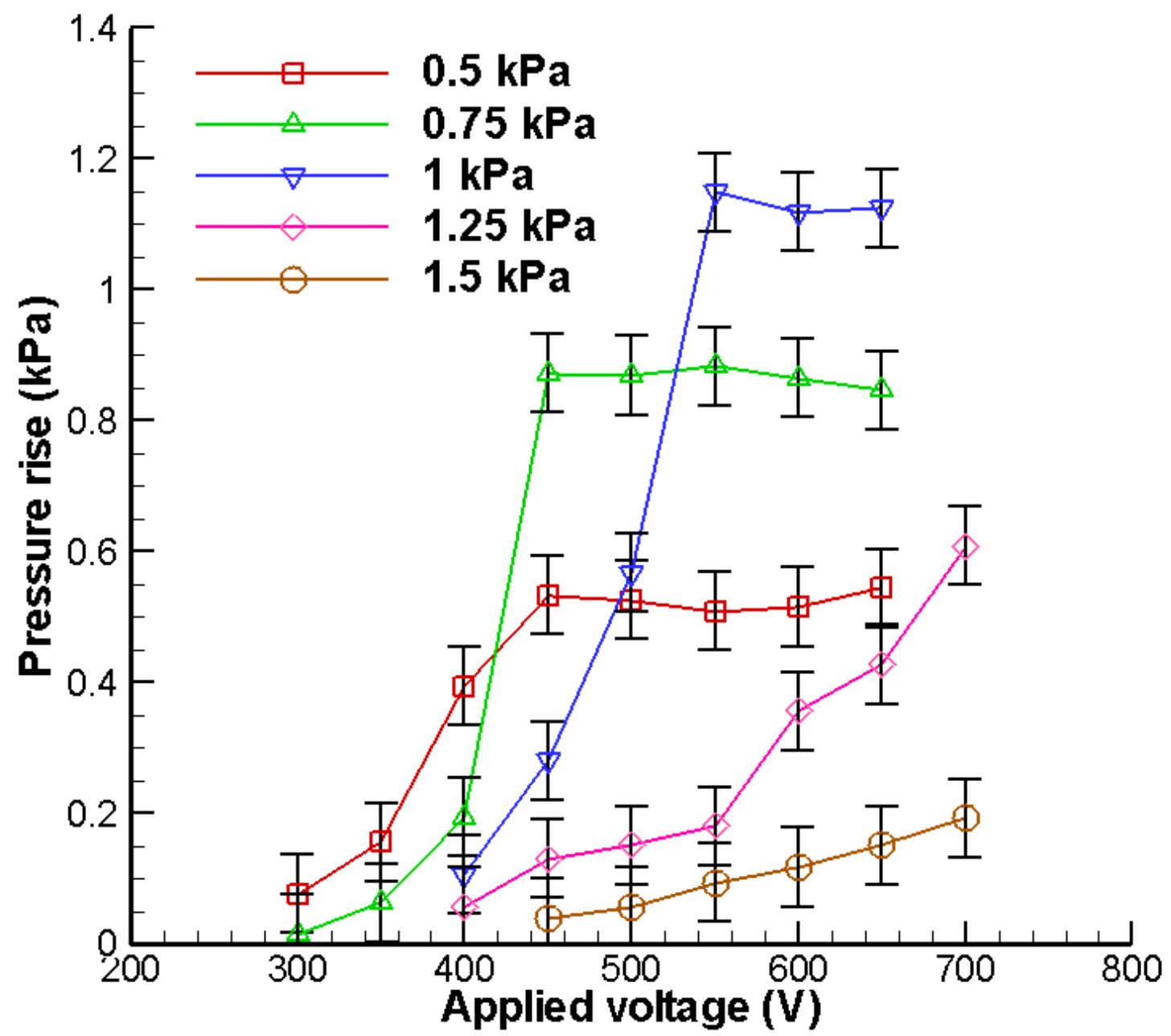

Figure 13. Measured pressure rise with applied voltage for different initial pressures. Once the diaphragm is fully zipped, no further pressure rise is observed.

At voltages above $400 \mathrm{~V}$ and for the lower inlet pressures, the phenomenon of dielectric charging was observed. This effect is caused when the dielectric is electrically charged and the diaphragm continues to stick to the electrode even after the voltage has been turned off [21].

The segment-wise model developed here is applied for the experimental conditions described here, and the predictions are compared with the experimental results. A sample comparison of the diaphragm deflection and pressure rise for an inlet pressure of $1 \mathrm{kPa}$ is shown in Figure 14. The model predictions agree quite well with the experimental results. Figure 15 and Figure 16 show the difference between the model predictions and experimental results for all the results obtained in terms of diaphragm deflection and pressure rise, respectively. The model predicts the diaphragm deflection to within $\pm 10 \%$ for most of the data points. The pressure rise predictions deviate from the experimental results at lower pressure rises, but in general, agree to within $\pm 20 \%$. Deviations in this comparison are attributed to uncertainties in the calculation of the system dead volume, and the dielectric layer thickness $( \pm 1 \mu \mathrm{m})$. 


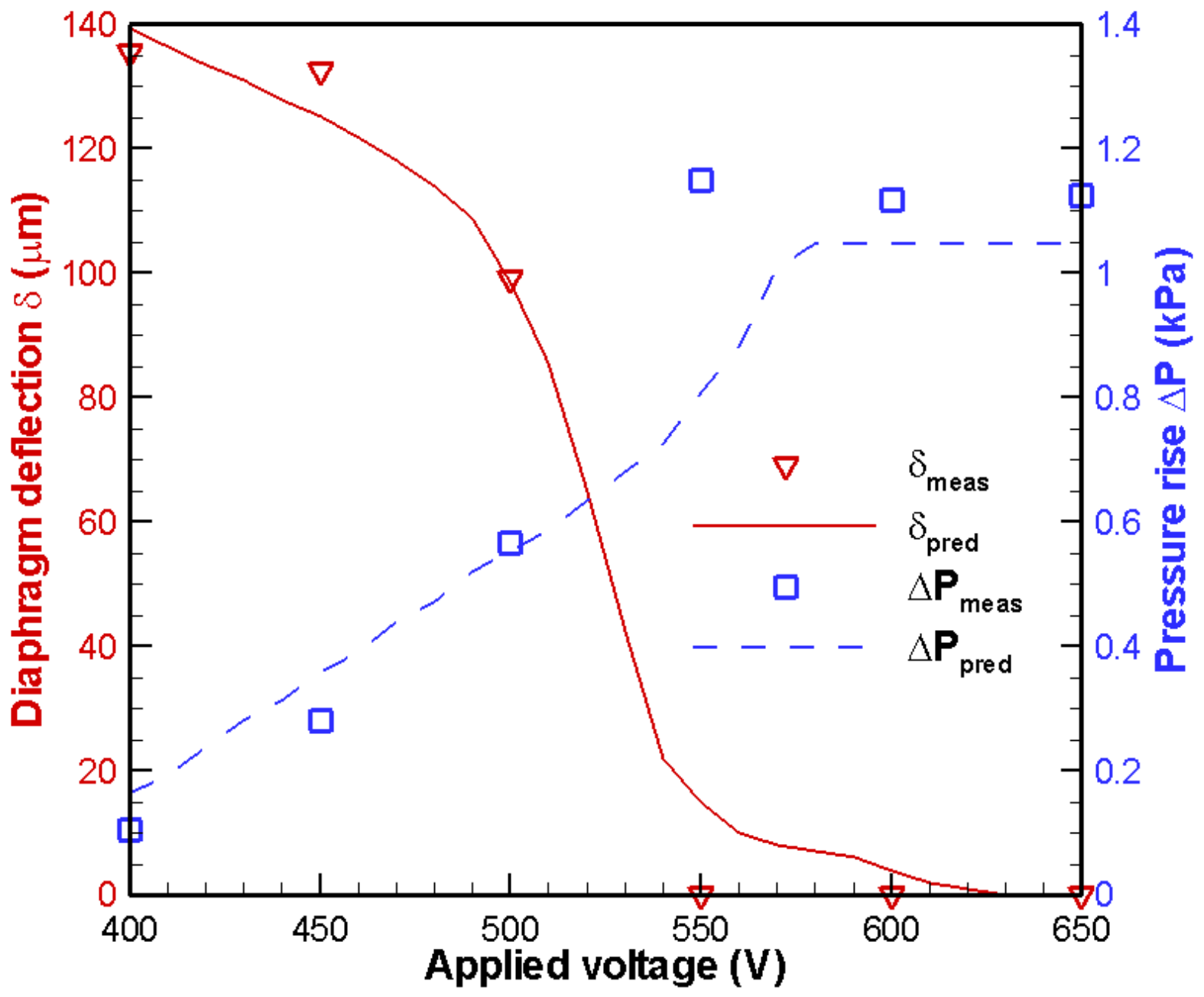

Figure 14. Comparison of predictions from the model and experimental results for an inlet pressure of $1 \mathrm{kPa}$. 


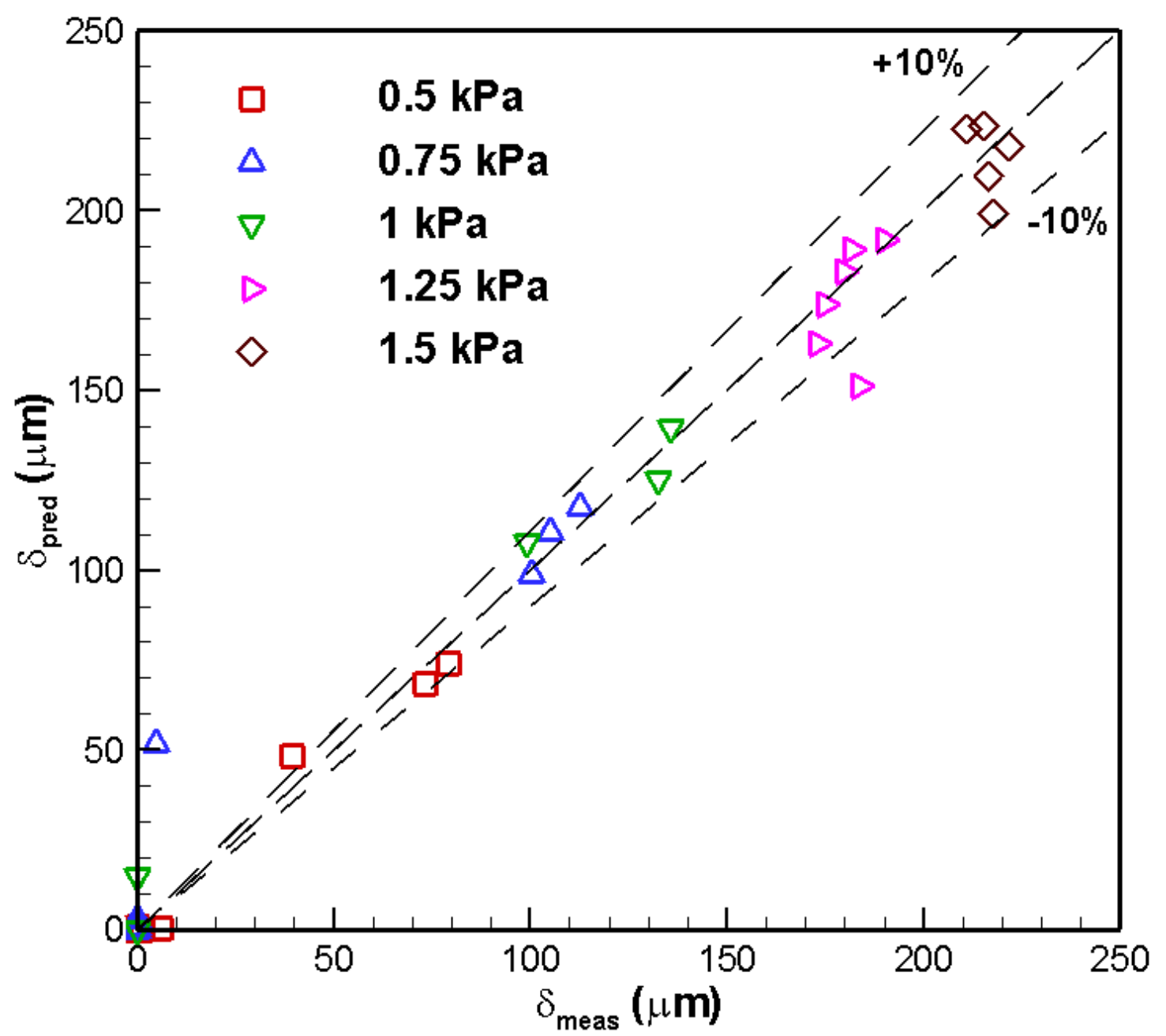

Figure 15. Comparison of predicted diaphragm deflection ( $\delta_{\text {pred }}$ ) against measured diaphragm deflection $\left(\delta_{\text {meas }}\right)$ for different inlet pressures. 


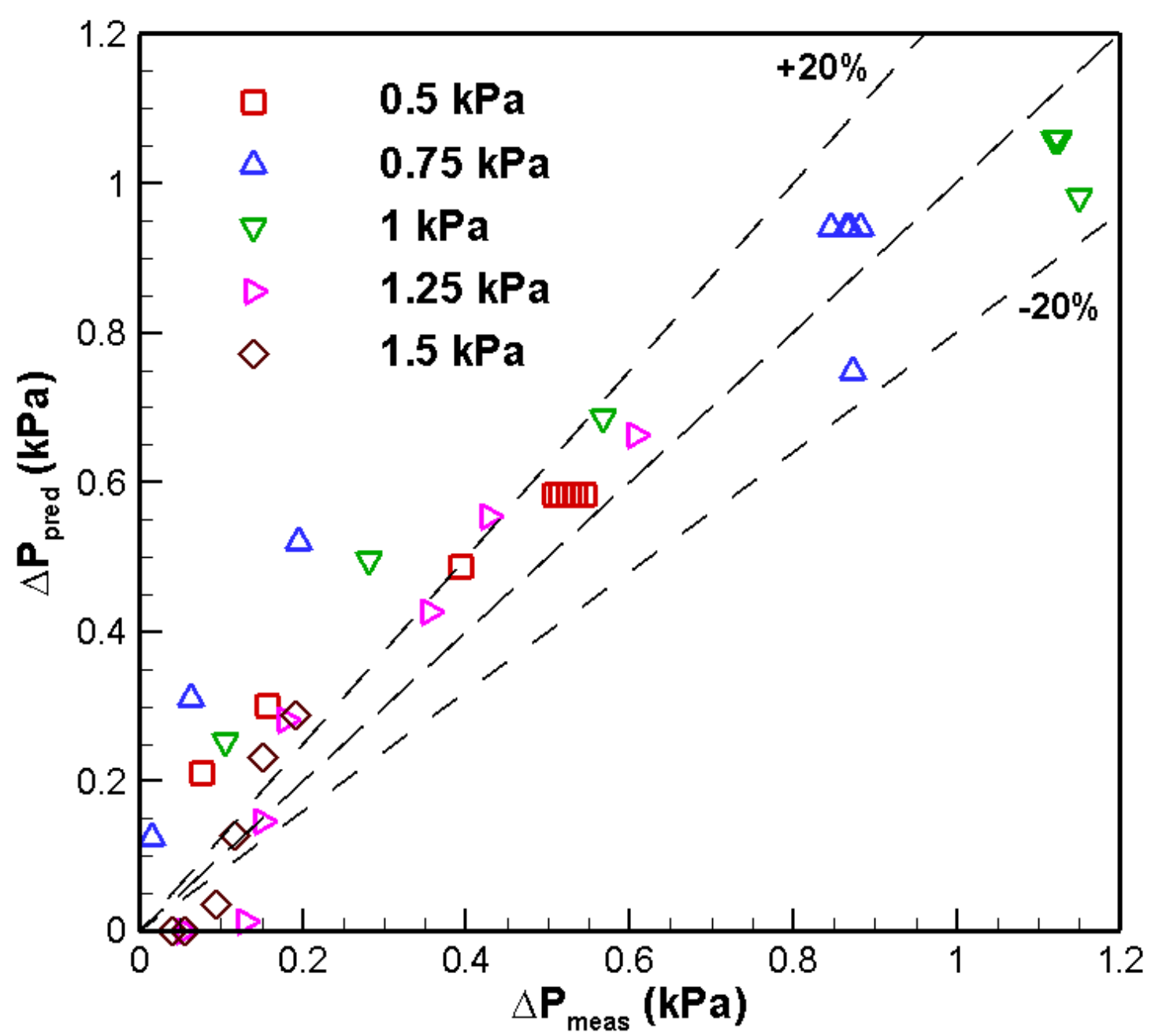

Figure 16. Comparison of predicted pressure rise $\left(\Delta P_{\text {pred }}\right)$ against measured pressure rise $\left(\Delta P_{\text {meas }}\right)$ for different inlet pressures.

\section{CONCLUSIONS}

A novel modeling approach is developed for analyzing the operation of an electrostatically actuated diaphragm compressor. The domain is divided into multiple radial segments and a force balance applied to each segment to estimate a local pull-down voltage. The model simulates the zipping actuation of the diaphragm by initiating the force balance calculations at the circumference and proceeding towards the center. The model is quasi-static and assumes infinitesimal progressive zipping of the diaphragm. Dynamic effects such as inertial forces and damping force of the compressed gas are not considered.

Predictions from the model show reasonable agreement with a lumped force balance model from the literature. An experimental test set-up was also constructed to experimentally validate the model predictions. The diaphragm deflection and pressure rise were measured as a function of applied voltage. The experimental results showed good agreement with model predictions.

The model predicts a required operating voltage of approximately $400 \mathrm{~V}$ for compressing refrigerant R134a gas by $30 \mathrm{kPa}$. Though the pressure rise is smaller than that required for a practical electronics cooling 
application, it is believed that an array of diaphragm compressors can be constructed to work in series to meet the requirements. Cost-effective means for fabricating the compressor chambers and coating the chamber and diaphragm with dielectric would need to be worked out before practical implementation.

\section{Acknowledgements}

The authors acknowledge financial support for this work from members of the Cooling Technologies Research Center (www.ecn.purdue.edu/CTRC), a National Science Foundation Industry/University Cooperative Research Center at Purdue University. We would also like to thank Dr. Lorenzo Cremaschi of Oklahoma State University for his assistance with this work.

\section{APPENDIX}

In principle, the diaphragm compressor can generate an arbitrarily high pressure rise (neglecting any dead volume in the chamber) so long as a sufficiently high voltage is applied and electric breakdown of the dielectric layers is prevented. However, in practice, the primary limitation on pressure rise comes from the elastic deformation limit of the diaphragm material. The metallized Kapton considered in this work has a yield point strain of 3\% [19]. Plastic deformation of the diaphragm beyond its elastic limit is undesirable as it is irreversible.

For a circular circumferentially clamped diaphragm of radius $R$, the deflection at any radial location $r$ under a gas pressure of $P_{\text {gas }}$ is given as [22]:

$$
y=\frac{12 \cdot\left(1-v^{2}\right) \cdot R^{4} \cdot P_{g a s}}{k^{2} \cdot E \cdot w^{3}}\left[\frac{I_{0}\left(\frac{k \cdot r}{R}\right)-I_{0}(k)}{2 \cdot k \cdot I_{1}(k)}-\frac{R^{2}-r^{2}}{4 \cdot R^{2}}\right]
$$

where $I_{0}$ and $I_{1}$ are the modified Bessel's functions of the first kind and zeroth and first order, respectively. The tension parameter $k$ is calculated as:

$$
k=\frac{R}{w} \cdot \sqrt{\frac{12 \cdot\left(1-v^{2}\right) \cdot \sigma_{r e s}}{E}}
$$

Based on the deflected diaphragm shape calculated using Equation (A1), a new diaphragm radius $R^{\prime}$ is calculated. Finally, the strain on the diaphragm is estimated as:

$$
\theta=\frac{R^{\prime}}{R}
$$

This strain must $\leq 3 \%$ to ensure that the deformation is elastic. This places a limit on the maximum gas pressure the diaphragm can withstand:

$$
\Delta P_{\max }=f\left(R, w, E, v, \sigma_{\text {res }}\right)
$$

Figure A1 shows the maximum allowable pressure for different diaphragm thicknesses as a function of the diaphragm radius for a Kapton diaphragm. Clearly, thicker diaphragms of smaller radius can withstand higher pressure rises. 


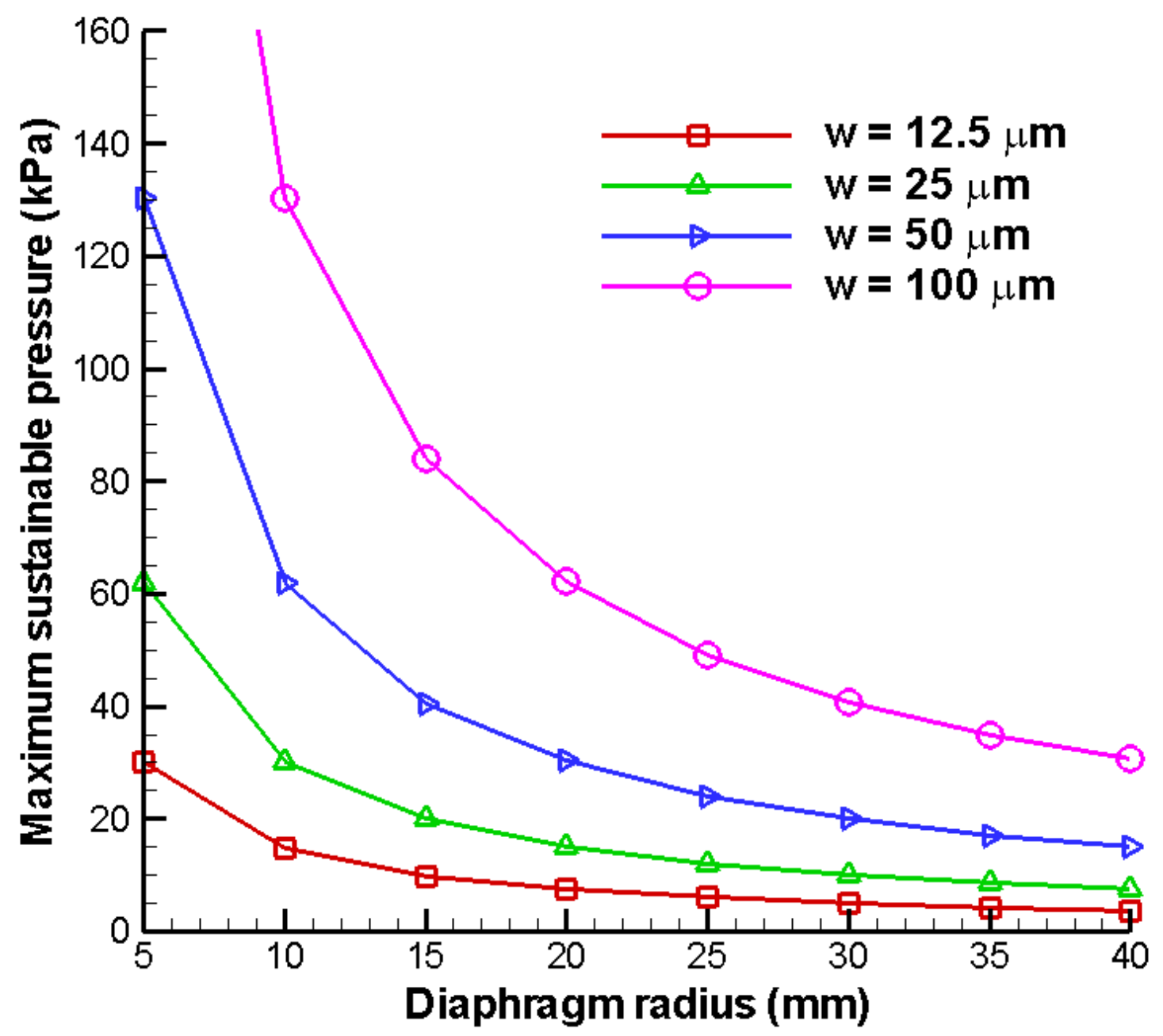

Figure A1. Maximum sustainable pressure rise for different radii $(R)$ and thicknesses $(w)$ of the diaphragm.

\section{REFERENCES}

[1] Moore, G.E., 1965, “Cramming more components onto integrated circuits," Electronics Journal, Vol. 38, pp. 82-85.

[2] International Technology Roadmap for Semiconductors, 2006 edition, "Assembly and packaging," Semiconductor Industry Association.

[3] Krishnan, S., Garimella, S. V., Chrysler, G. M., Mahajan, R. V., 2007, “Towards a thermal Moore's law," IEEE Transactions on Advanced Packaging, Vol. 30, pp. 462-474.

[4] Garimella, S. V., 2006, "Advances in mesoscale thermal management technologies for microelectronics," Microelectronics Journal, Vol. 37, pp. 1165-1185.

[5] Cremaschi, L., Groll, E. A., Garimella, S. V., 2007, "Performance potential and challenges of future refrigeration-based electronics cooling approaches," Proceedings of THERMES 2007 Conference on Thermal Challenges in Next Generation Electronic Systems, Santa Fe, New Mexico, 7-10 January, 2007. 
[6] Trutassanawin, S., Groll, E. A., Garimella, S. V. and Cremaschi, L., 2006, "Experimental investigation of a miniature-scale refrigeration system for electronics cooling," IEEE Transactions on Components and Packaging Technologies, Vol. 29, pp. 678-687.

[7] Pelesko, J. A., Chen, X. Y., 2003, "Electrostatic deflections of circular elastic membranes," Journal of Electrostatics, Vol. 57, pp. 1-12.

[8] Osterberg, P. M., Senturia, S. D., 1997, "M-TEST: a test chip for MEMS material property measurement using electrostatically actuated test structures," Journal of Microelectromechanical Systems, Vol. 6, pp. 107-118.

[9] Cheng, J., Zhe, J., Wu, X., Farmer, K. R., Modi, V., Frechette, L., 2002, “Analytical and FEM simulation pull-in study on deformable electrostatic micro actuators," Technical Proceedings of the 2002 International Conference on Modeling and Simulation of Microsystems - MSM 2002, pp. 298301.

[10] Cabuz, C., Cabuz, E. I., Herb, W., R., Rolfer, T., Zook, D., 1999, "Mesoscopic sampler based on 3D arrays of electrostatically actuated diaphragms," Proc. of the 10th Int. Conf. on Solid-State Sensors and Actuators, Transducers'99, June 7-12, Sendai, Japan.

[11] Cabuz, C., Herb, W., R., Cabuz, E. I., Lu, S. T., 2001, “The dual diaphragm pump,” MEMS 2001 14th IEEE International Conference on Micro Electro Mechanical Systems, pp. 519-522.

[12] Athavale, M., Li, H. Y., Yang, H. Q., Przekwas, A. J., Cabuz, C., Herb, W., 1999, "Coupled electrostatics-structures-fluidic simulations of a bead mesopump," IMECE, Nashville, TN, pp. 459465 .

[13] Zengerle, R., Ulrich, J., Kluge, S., Richter, M., Richter, A., 1995, “A bidirectional silicon micropump," Sensors and Actuators, A: Physical, Vol. 50, pp. 81-86.

[14] Shannon, M. A., Philpott, M. L., Miller, N. R., Bullard, C. W., et al., 1999, "Integrated mesoscopic cooler circuits (IMCCS)," Proceedings of the ASME, Advanced Energy System Division pp.14-17.

[15] Saif, M. T. A., Alaca, B. E. and Sehitoglu, H., 1999, "Analytical modeling of electrostatic membrane actuator for micro pumps," J. MEMS, Vol. 8, pp. 335-345.

[16] Senturia, S.D., 2001, "Microsystem Design," Kluwer Academic Publishers.

[17] DiGiovanni, M., 1982, "Flat and corrugated diaphragm design handbook," Marcel Dekker, New York.

[18] Chowdhury, S., Ahmadi, M., Miller, W. C., 2004, "A new analytical model for the pull-in voltage of clamped diaphragms subject to electrostatic force," Sensor Letters, Vol. 2, pp. 106-112.

[19] DuPont, Inc., 2006, "DuPont kapton HN polyimide film data sheet," http://www2.dupont.com/Kapton/en_US/assets/downloads/pdf/HN_datasheet.pdf.

[20] The Mathworks, Inc., Natick, MA, USA, 2007.

[21] Yuan, X., Cherepko, S., Hwang, J. and Goldsmith, C. L., 2004, "Initial observation and analysis of dielectric-charging effects on RF MEMS capacitive switches," IEEE MTT-S International Microwave Symposium Digest, Vol.3, pp. 1943-6.

[22] Sheplak, M., Seiner, J. M., Breuer, K. S., Schmidt, M. A., 1999, “A MEMS microphone for aeroacoustic measurements," AIAA Paper 99-0606, Proceedings, 37th AIAA Aerospace Sciences Meeting, Reno, NV. 